\title{
Electrocatalytic Oxidation of Methanol and Ethanol by Carbon Ceramic Electrode Modified with Ni/AI LDH Nanoparticles
}

\author{
Ghasem KARIM-NEZHAD*, Sara PASHAZADEH, Ali PASHAZADEH \\ Department of Chemistry, Payame Noor University, PO Box 19395-3697, Tehran, Iran
}

\begin{abstract}
A Ni/Al layered double hydroxide (LDH) nanoparticle modified carbon ceramic electrode (Ni/Al LDH/NMCC) was fabricated and used for the electrocatalytic oxidation of methanol and ethanol in alkaline media. Cyclic voltammetric (CV) studies showed that it gave a significantly higher activity for methanol and ethanol oxidation and can be used as an electrocatalytic anode for fuel cells. The kinetic parameters of the electron transfer coefficient $(\alpha)$ and number of electrons involved in the rate determining step $\left(n_{\alpha}\right)$ for the oxidation of methanol and ethanol were determined using CV. The anodic currents showed a linear dependence on the concentration of methanol and ethanol.
\end{abstract}

Key words: nickel; aluminium; layered double hydroxide; modified carbon ceramic electrode; electrocatalytic oxidation; methanol; ethanol CLC number: O643 Document code: A

Received 10 July 2012. Accepted 30 August 2012.

*Corresponding author. Tel: +98-461-2349868; Fax: +98-461-2332556; E-mail: g.knezhad@gmail.com

English edition available online at Elsevier ScienceDirect (http://www.sciencedirect.com/science/journal/18722067).

Fuel cells have attracted much attention as an alternative power supply for many applications [1]. Research and development activities on direct alcohol fuel cells (DAFC) have increased tremendously in recent years. There are two conventional types of DAFC: direct methanol fuel cell (DMFC) and direct ethanol fuel cell (DEFC) with methanol and ethanol as fuel. Each fuel has advantages and disadvantages. The disadvantages of utilizing methanol as a fuel are methanol crossover through the Nafion membrane to the oxygen electrode and anode poisoning by strongly adsorbed intermediates (mainly CO) [2-5]. Ethanol is an alternative fuel because it can be produced from agricultural raw materials, which helps diminish global concentrations of greenhouse gases. Ethanol has a lower crossover rate and impairs cathode performance less than methanol [5].

Modified electrodes can provide electrochemists with the ability to tailor electrode reactivity to obtain highly sensitive and selective signals [6]. Modified electrodes have recently received much interest because they have a wide range of potential applications in electrochemical technology, energy conversion, and chemical analysis, as well as possible applications in information storage, electrochromism devices, and visual displays [7]. Modified carbon electrodes are widely used [8] because of their low background current, wide potential window, chemical inertness, low cost, and they are suitable for many applications [9-11]. Sol-gel electrochemistry has drawn extensive interest over the past decades for its remarkable uses in electrochemical studies and applications [12-15]. Increasing interest has been fo- cused on sol-gel derived carbon ceramic electrodes (CCEs). These are generally prepared by doping graphite powder into a silicate gel matrix $[16,17]$. This electrode was developed in the early 1990s $[18,19]$ and it is robust and easy to prepare. A CCE can be easily modified by (i) doping the sol used for electrode preparation, (ii) covalent modification of carbon microparticles, (iii) covalent modification of the sol-gel precursor, and (iv) adsorption on the electrode surface [18].

Because CCEs have the advantages of low cost, high stability, good surface-renewal repeatability, and ease of preparation and modification, much work has been devoted to preparing CCEs modified with different electrochemically active species [19].

Layered double hydroxides (LDHs), which are hydrotalcite-like materials, are a class of two-dimensional nanostructured anionic clays. The positively charged layers contain edge-shared metal M (II) and M (III) hydroxide octahedra with charges neutralized by anions located in the interlayer spacing or at the edges of the lamella. Electrodes modified with films of Ni/Al LDHs have attracted considerable attention [19-23]. Ni/Al LDH films have been reported to catalyze the electrochemical oxidation of primary alcohols and sugars [24,25]. They have been used as ion selective electrodes for the potentiometric sensing of anions such as nitrate and chloride [26], and for the amperometric sensing of methanol, mannitol, and glucose [27]. Wang et al. have reported the use of a Ni/Al LDH film modified GC electrode for the electrocatalytic oxidation of methanol [28]. 
The purpose of the present work is to prepare a $\mathrm{Ni}-\mathrm{Al}$ LDH nanoparticle modified carbon ceramic electrode and investigate its electrocatalytic properties for the oxidation of methanol and ethanol.

\section{Experimental}

\subsection{Reagents and instrumentation}

Methyltrimethoxysilane (MTMOS) was purchased from Fluka and used without further purification. Methanol, $\mathrm{HCl}$, ethanol, high purity graphite powder, and the other reagents used were analytical reagent grade provided by Merck and Fluka. All solutions were prepared with doubly distilled water. Electrochemical measurements were carried out in a conventional three-electrode cell powered by an electrochemical system comprising an AUTOLAB system with PGSTAT12 boards (Eco Chemie, Utrecht, and The Netherlands). The system was run by a PC using the GPES 4.9 software. A platinum wire positioned as close to the working electrode as possible by means of a Luggin capillary was employed as the counter electrode. The Ni/Al LDH/NMCC electrode was the working electrode. All potentials were measured with respect to the $\mathrm{Ag}, \mathrm{AgCl}$ couple. All experiments were performed at room temperature $(25 \pm$ $\left.2{ }^{\circ} \mathrm{C}\right)$.

\subsection{Preparation of Ni/Al LDH nanoparticles}

The Ni/Al LDHs nanoparticles were prepared by the hydrothermal method [29]. A series of Ni/Al LDHs with the nominal $\mathrm{Ni}^{2+} / \mathrm{Al}^{3+}$ atomic ratio of $3 / 1$ were prepared by hydrothermal reaction at $180^{\circ} \mathrm{C}$. All these were prepared as follows. Appropriate amounts of $\mathrm{NiSO}_{4} \cdot 6 \mathrm{H}_{2} \mathrm{O}$ and $\mathrm{Al}_{2}\left(\mathrm{SO}_{4}\right)_{3} \cdot 18 \mathrm{H}_{2} \mathrm{O}\left(\mathrm{Ni}^{2+} / \mathrm{Al}^{3+}=3 / 1\right.$ molar ratio) were dissolved in deionized water $(40 \mathrm{ml})$. An aqueous solution of $0.5 \mathrm{~mol} / \mathrm{L} \mathrm{Na}_{2} \mathrm{CO}_{3}$ and $3 \mathrm{~mol} / \mathrm{L} \mathrm{NaOH}$ was added to the above solution dropwise with vigorous stirring to adjust the $\mathrm{pH}$ of the solution. After that, the suspension was transferred into a $50 \mathrm{ml}$ stainless steel Teflon-lined autoclave and heated at $180^{\circ} \mathrm{C}$ for the appropriate time, and then cooled to room temperature naturally. The resulting product was filtrated and washed several times with distilled water and absolute ethanol. The apple-green solid was then dried at room temperature for $12 \mathrm{~h}$. XRD results [29] indicated that the size of the Ni/Al LDH particles was on the nanoscale.

\subsection{Preparation of $\mathrm{Ni} / \mathrm{Al} \mathrm{LDH} / \mathrm{NMCC}$ electrode}

Unmodified and modified carbon ceramic electrode electrodes were prepared using the procedure described by Tsionsky et al. [18]. The fabrication procedure of the Ni/Al
$\mathrm{LDH} / \mathrm{NMCC}$ electrode was as follows. MTMOS $(0.2 \mathrm{ml})$, methanol $(0.6 \mathrm{ml})$, and $20 \mu \mathrm{HCl}(11 \mathrm{~mol} / \mathrm{L})$ were mixed and stirred for 2 min until a homogeneous gel solution appeared. Then $0.5 \mathrm{~g}$ graphite powder and $\mathrm{Ni} / \mathrm{Al} \mathrm{LDH}$ nanoparticle powder in a ratio of 9:1 were added, and the resulting mixture was shaken for an additional $5 \mathrm{~min}$. The mixture was packed into a Teflon tube $(5 \mathrm{~cm}$ length and 2 $\mathrm{mm}$ inner diameter) and dried for $48 \mathrm{~h}$ at room temperature. Then the electrode was polished with polishing paper and rinsed with distilled water. The bare carbon ceramic electrode was made by the same procedure but without adding the Ni/Al LDH nanoparticles to the graphite powder. The electric contact was made with a copper wire through the back of the electrode. Then the electrode was placed in 0.1 $\mathrm{mol} / \mathrm{L} \mathrm{NaOH}$ and the electrode potential was cycled between 0 and $700 \mathrm{mV}$ (vs $\mathrm{Ag} / \mathrm{AgCl}$ ) at a scan rate of $50 \mathrm{mV} / \mathrm{s}$ for 5 cycles in a cyclic voltammetric regime until a stable voltammogram was obtained.

\section{Results and discussion}

The Ni/Al LDH nanoparticle modified carbon ceramic (Ni/Al LDH/NMCC) electrode was prepared as a new type of electrode. For the activation of the electrode surface, the electrode was placed in $0.1 \mathrm{~mol} / \mathrm{L} \mathrm{NaOH}$ and the electrode potential was cycled between 0 and $700 \mathrm{mV}$ (vs $\mathrm{Ag} / \mathrm{AgCl}$ ) at a scan rate of $50 \mathrm{mV} / \mathrm{s}$ for 5 cycles in a cyclic voltammetry regime. Next the cyclic voltammograms of the modified electrode were recorded in $0.1 \mathrm{~mol} / \mathrm{L} \mathrm{NaOH}$ at various potential sweep rates (Fig. 1(a)). A pair of redox peaks was observed, which corresponded to the conversion between the different oxidation states of $\mathrm{Ni}$ by the reaction

$$
\mathrm{LDH}-\mathrm{Ni}(\mathrm{II})+\mathrm{OH}^{-} \leftrightarrow \mathrm{LDH}\left(\mathrm{OH}^{-}\right)-\mathrm{Ni}(\mathrm{III})+\mathrm{e}^{-}
$$

With the increase of the scan rate, the redox current increased, the anodic peak shifted toward positive potential to overlap with the oxygen evolution peak, and the cathodic peak was shifted toward negative potential. The currents of the peaks $\left(I_{\mathrm{pa}}\right.$ and $\left.I_{\mathrm{pc}}\right)$ were proportional to the sweep rates in the range of 3-100 mV/s (Fig. 1(b)), which showed the electrochemical activity of the surface redox couple. The value of $\Gamma^{*}$ was $1.31 \times 10^{-4} \mathrm{~mol} / \mathrm{cm}^{2}$ for $n=1$, which was calculated from the slope of anodic peak current versus scan rate using [30]:

$$
I_{\mathrm{p}}=\left(n^{2} \mathrm{~F}^{2} / 4 \mathrm{R} T\right) v A \Gamma
$$

where $v$ is the sweep rate, $A$ is the geometric surface area, and $\Gamma$ is the surface coverage of the redox species.

An objective of the present study was to fabricate a modified electrode for the electrocatalytic oxidation of methanol and ethanol. In order to test the electrocatalytic activity of the Ni/Al-LDH/NMCC electrode, cyclic voltammograms were obtained in the presence and absence of methanol at the bare (Fig. 2(1)) and Ni/Al LDH/NMCC 

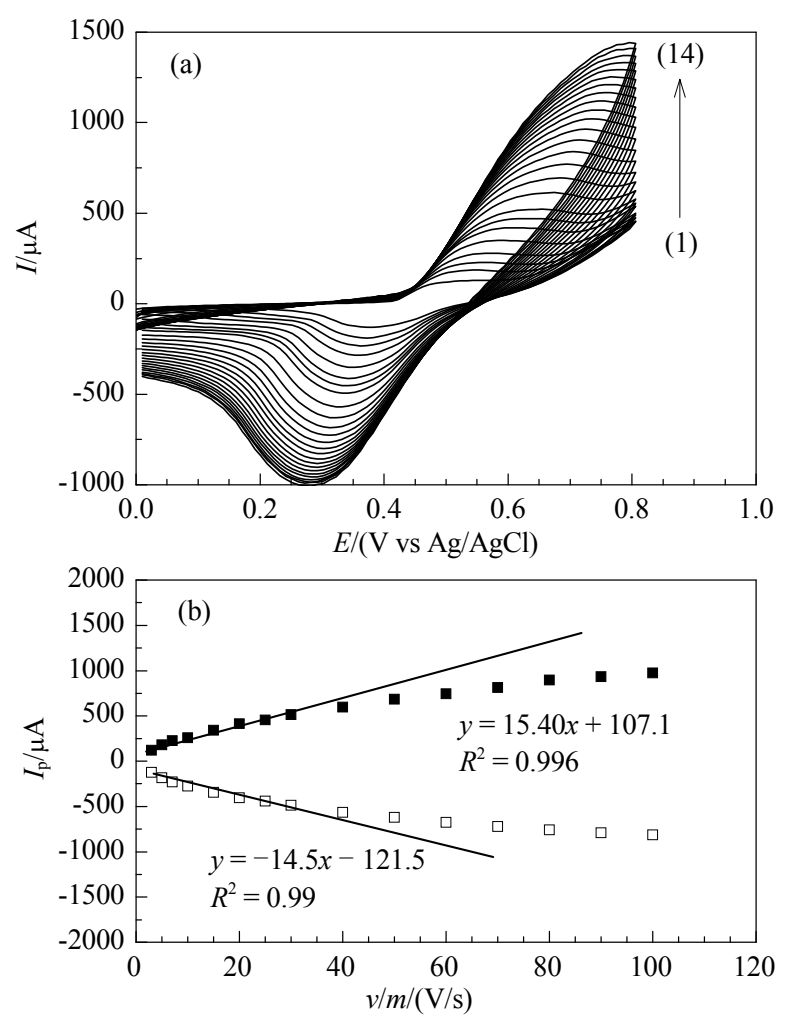

Fig. 1. Cyclic voltammetric curves of $\mathrm{Ni} / \mathrm{Al} \mathrm{LDH} / \mathrm{NMCC}$ electrode in $0.1 \mathrm{~mol} / \mathrm{L} \mathrm{NaOH}$ at various potential scan rates ((1) $3 \mathrm{mV} / \mathrm{s}$, (2) 5 $\mathrm{mV} / \mathrm{s}$, (3) $7 \mathrm{mV} / \mathrm{s}$, (4) $15 \mathrm{mV} / \mathrm{s}$, (5) $20 \mathrm{mV} / \mathrm{s}$, (6) $25 \mathrm{mV} / \mathrm{s}$, (7) $30 \mathrm{mV} / \mathrm{s}$ (8) $40 \mathrm{mV} / \mathrm{s}$, (9) $50 \mathrm{mV} / \mathrm{s}$, (10) $60 \mathrm{mV} / \mathrm{s}$, (11) $70 \mathrm{mV} / \mathrm{s}$, (12) $80 \mathrm{mV} / \mathrm{s}$, (13) $90 \mathrm{mV} / \mathrm{s}$, and (14) $100 \mathrm{mV} / \mathrm{s}$ ) (a) and anodic and cathodic peak currents vs scan rate $\left(\cdot \boldsymbol{~ a n d ~}^{\mathrm{a}}\right)$ and trendilines $(-)(\mathrm{b})$.

(Fig. 2(2)) electrodes. At the bare electrode, no anodic current due to the oxidation of methanol was observed. However, for the Ni/Al-LDH/NMCC electrode, a large anodic peak was observed. Compared with the bare carbon ceramic electrode, the electrochemical oxidation of methanol was greatly increased at the Ni/Al-LDH/NMCC electrode, indi-

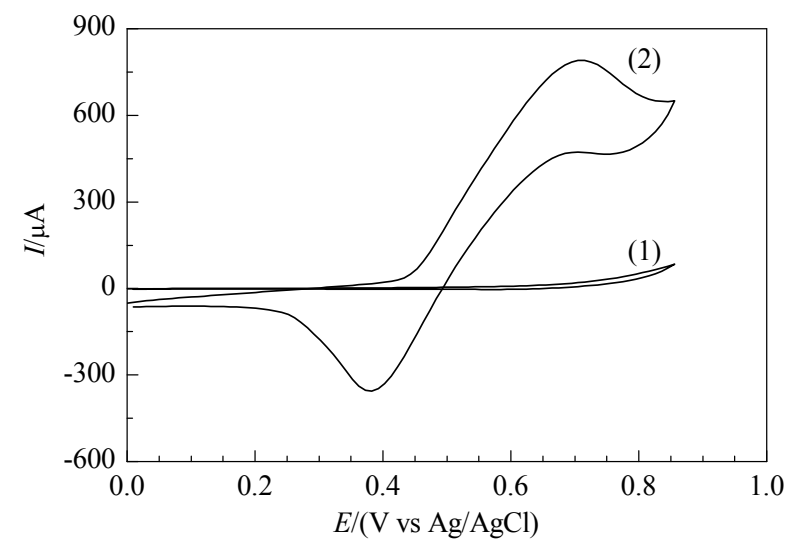

Fig. 2. Cyclic voltammograms of bare carbon ceramic (1) and $\mathrm{Ni} / \mathrm{Al}-\mathrm{LDH} / \mathrm{NMCC}$ (2) electrode in $0.1 \mathrm{~mol} / \mathrm{L} \mathrm{NaOH}$ containing 0.05 $\mathrm{mol} / \mathrm{L}$ methanol. cating that the anodic oxidation of methanol was catalyzed at the Ni/Al-LDH/NMCC electrode. The same behavior was observed for ethanol at the surface of the Ni/Al-LDH/NMCC electrode (Fig. 3).

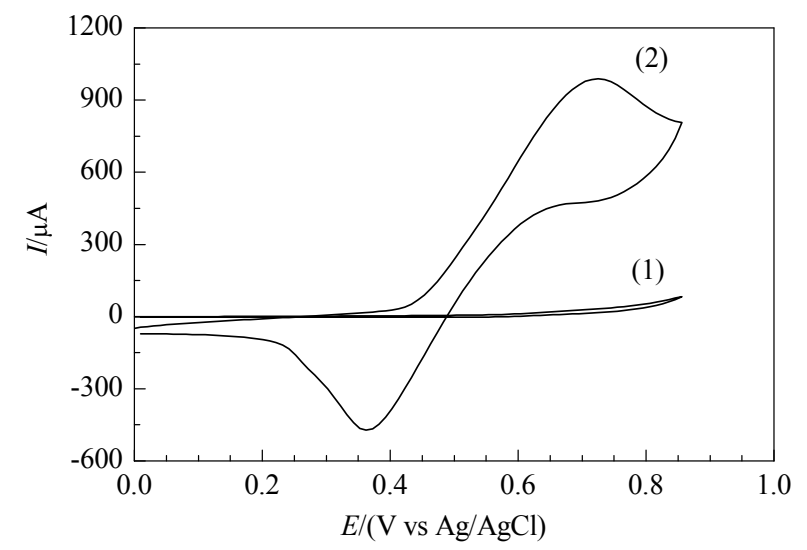

Fig. 3. Cyclic voltammograms of bare carbon ceramic (1) and $\mathrm{Ni} / \mathrm{Al}-\mathrm{LDH} / \mathrm{NMCC}$ (2) electrode in $0.1 \mathrm{~mol} / \mathrm{L} \mathrm{NaOH}$ containing 0.05 $\mathrm{mol} / \mathrm{L}$ ethanol.

Figure 4 shows the dependence of the voltammetric response of the Ni/Al-LDH/NMCC electrode on the methanol concentration, which showed an increase in the anodic peak current and a decrease in the cathodic peak current. The plot of $I$ versus methanol concentration was linear in the concentration range 10-100 mmol/L. Similar cyclic voltammograms were observed for ethanol and the anodic peak currents depended on ethanol concentration in the range of 10-100 mmol/L (Fig. 5).

To get information on the catalytic mechanism, the cyclic voltammograms of $0.050 \mathrm{~mol} / \mathrm{L}$ methanol and ethanol at

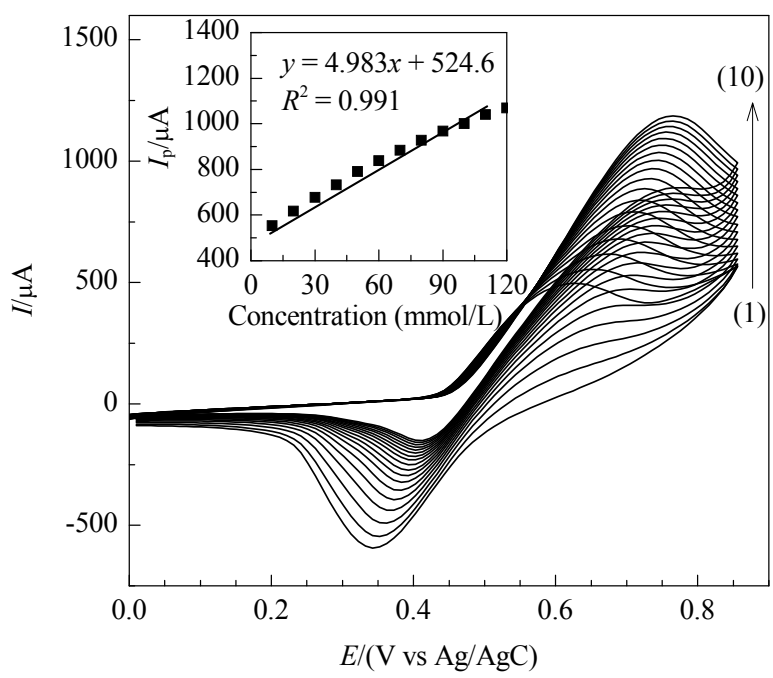

Fig. 4. Cyclic voltammograms with different concentrations of methanol at the $\mathrm{Ni} / \mathrm{Al} \mathrm{LDH} / \mathrm{NMCC}$ electrode in $0.1 \mathrm{~mol} / \mathrm{L} \mathrm{NaOH}$ at a scan rate of $50 \mathrm{mV} / \mathrm{s}$. Concentrations of methanol for (1) to (10) were $0.01,0.02,0.03,0.04,0.05,0.06,0.07,0.08,0.09$, and $0.1 \mathrm{~mol} / \mathrm{L}$. 


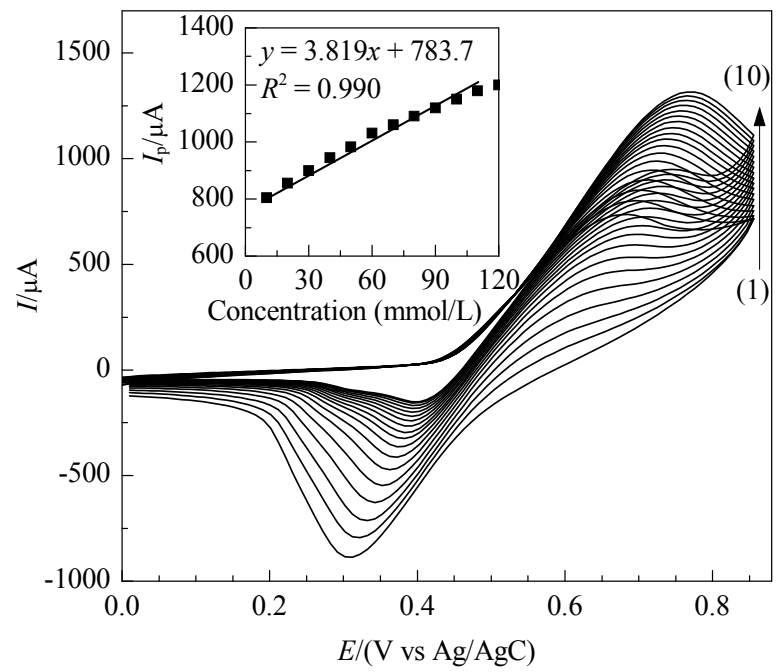

Fig. 5. Cyclic voltammograms with different concentrations of ethanol at the Ni/Al LDH/NMCC electrode in $0.1 \mathrm{~mol} / \mathrm{L} \mathrm{NaOH}$ at a scan rate of $50 \mathrm{mV} / \mathrm{s}$. Concentrations of ethanol for (1) to (10) were $0.01,0.02,0.03,0.04,0.05,0.06,0.07,0.08,0.09$, and $0.1 \mathrm{~mol} / \mathrm{L}$.

different scan rates were recorded (not shown). The anodic oxidation current with methanol was proportional to the square root of the scan rate, indicating that at a sufficiently positive potential, the reaction was controlled by methanol diffusion. This is the ideal situation for quantitative applications.

It was also observed that by increasing the sweep rate, the peak potential for the catalytic oxidation of methanol was shifted to more positive values and the plot of peak current versus square root of scan rate deviated from linearity, which suggested kinetic control in the reaction between the redox sites of the modifier and methanol. These results showed that the cross exchange process between methanol and the redox sites of the Ni-Al LDH couple and the diffusion of methanol controlled the overall electrochemical oxidation of methanol at the Ni/Al-LDH/NMCC electrode. The same results were observed with ethanol.

It has been reported in the literature [31] that this behavior is typical of the mediated oxidation of methanol and ethanol, which are

$$
\begin{gathered}
\mathrm{LDH}-\mathrm{Ni}(\mathrm{II})+\mathrm{OH}^{-} \leftrightarrow \mathrm{LDH}\left(\mathrm{OH}^{-}\right)-\mathrm{Ni}(\mathrm{III})+\mathrm{e}^{-} \\
\mathrm{LDH}(\mathrm{OH})-\mathrm{Ni}(\mathrm{III})+\text { alcohol } \rightarrow \mathrm{LDH}-\mathrm{Ni}(\mathrm{II})+\mathrm{OH}^{-}+ \\
\text {oxidation products }
\end{gathered}
$$

To get information on the rate determining step, a Tafel slope was drawn using data from the rising part of the current voltage curve recorded at a scan rate of $5 \mathrm{mV} / \mathrm{s}$. A slope of $120.6 \mathrm{mV}$ per decade was obtained, which indicated that a one electron transfer was involved in the rate limiting step assuming a charge transfer coefficient $(\alpha)$ of 0.49 . The Tafel slope was also obtained from the linear relationship observed for $E_{\mathrm{p}}$ versus $\log v$ (not shown) by the following equation [32].

$$
E_{\mathrm{p}}=b / 2 \log v+\text { constant }
$$

From Eq. (II), the slope of $E_{\mathrm{p}}$ versus $\log v$ is $b / 2$, where $b$ is the Tafel slope. The slope of the plot of $E_{\mathrm{p}}$ versus $\log v$ is $\partial E_{\mathrm{p}} / \partial(\log v)$, which was found to be 78.119 . So $b=156.238$, which was in good agreement with the value obtained from the polarization measurements. This slope indicated that a one electron transfer process is the rate limiting step assuming a transfer coefficient of $\alpha=0.37$. For ethanol, similar results were obtained with a calculated transfer coefficient of 0.42 .

We present the effect of $\mathrm{NaOH}$ concentration on methanol oxidation at the Ni/Al-LDH/NMCC electrode in Fig. 6. With an increase in $\mathrm{OH}^{-}$concentration, the peak current of methanol oxidation increased first and then began to decrease remarkably at a $\mathrm{NaOH}$ concentration of $0.1 \mathrm{~mol} / \mathrm{L}$. The results indicated that the $\mathrm{OH}^{-}$ion participates in the oxidation of methanol and was detrimental to the oxidation of methanol because of competitive adsorption with methanol for the active cites. At a high $\mathrm{OH}^{-}$concentration $(>0.1$ $\mathrm{mol} / \mathrm{L}$ ), the current mainly came from the redox of the $\mathrm{Ni}(\mathrm{III}) / \mathrm{Ni}(\mathrm{II})$ couple because of the competitive adsorption on the active sites by $\mathrm{OH}^{-}$. To get a high oxidation current at a lower oxidation potential, $0.1 \mathrm{~mol} / \mathrm{L} \mathrm{NaOH}$ was chosen as the support electrolyte. For ethanol, similar results were obtained and shown in Fig. 7.

In Fig. 8, the Tafel slopes for the electro-oxidation of methanol at the $\mathrm{Ni} / \mathrm{Al}-\mathrm{LDH} / \mathrm{NMCC}$ electrode for various $\mathrm{NaOH}$ concentrations are shown. Figure 8 shows that the mechanism of the oxidation changed for $\mathrm{NaOH}$ concentra-

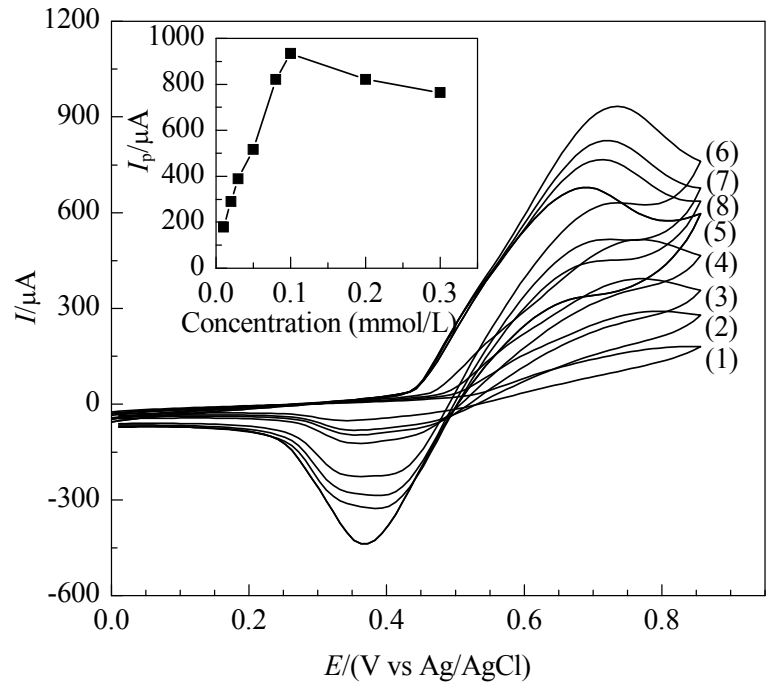

Fig. 6. Cyclic voltammograms of the $\mathrm{Ni} / \mathrm{Al} \mathrm{LDH} / \mathrm{NMCC}$ electrode in $0.05 \mathrm{~mol} / \mathrm{L}$ methanol containing different concentrations of $\mathrm{NaOH}$ at the scan rate of $50 \mathrm{mV} / \mathrm{s}$. The $\mathrm{NaOH}$ concentration was 0.01 (1), 0.02 (2), 0.03 (3), 0.05 (4), 0.08 (5), 0.1 (6), 0.2 (7), and 0.3 (8) mol/L. The inset displays the peak currents vs $\mathrm{NaOH}$ concentration. 


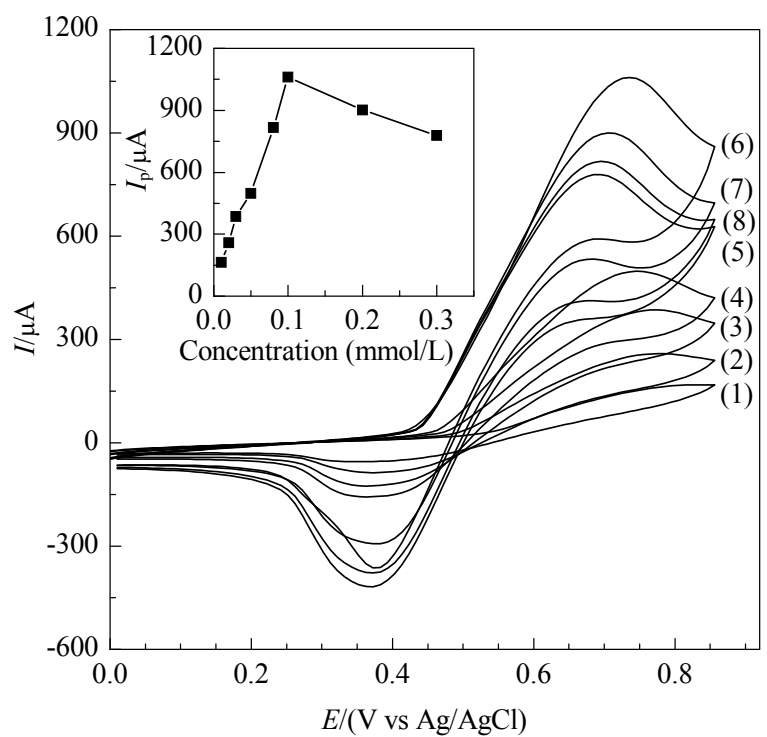

Fig. 7. Cyclic voltammograms of the Ni/Al LDH/NMCC electrode in $0.05 \mathrm{~mol} / \mathrm{L}$ ethanol containing different concentrations of $\mathrm{NaOH}$ at the scan rate of $50 \mathrm{mV} / \mathrm{s}$. The $\mathrm{NaOH}$ concentration was $0.01(1), 0.02$ (2), 0.03 (3), 0.05 (4), 0.08 (5), 0.1 (6), 0.2 (7), and 0.3 (8). The inset displays the peak currents vs $\mathrm{NaOH}$ concentration.

tions in the range of $0.01-0.1 \mathrm{~mol} / \mathrm{L}$ because the Tafel slopes were different. For the $\mathrm{NaOH}$ concentration of 0.1 , the Tafel slope was $0.1206 \mathrm{~V} /$ decade, which indicated a first electron transfer depending on the applied potential as the rate determining step. At $\mathrm{NaOH}$ concentrations of 0.05 , 0.02 , and $0.01 \mathrm{~mol} / \mathrm{L}$, the Tafel slopes were $0.136,0.170$, and $0.242 \mathrm{~V} /$ decade, respectively, and could indicate the presence of two different mechanisms operating simultaneously. On the other hand, the Tafel slope did not change at the $\mathrm{NaOH}$ concentration of $0.1 \mathrm{~mol} / \mathrm{L}$ for different methanol concentrations, and it was $0.120 \mathrm{~V} /$ decade. This means that a unique mechanism that does not depend on the methanol concentration operates at the $\mathrm{NaOH}$ concentration of 0.1 $\mathrm{mol} / \mathrm{L}$, and the rate determining step is the first electron transfer [33]. For ethanol, similar results were obtained (not shown). For the $\mathrm{NaOH}$ concentration of $0.1 \mathrm{~mol} / \mathrm{L}$, the Tafel slope was $0.120 \mathrm{~V} /$ decade. At $\mathrm{NaOH}$ concentrations of 0.05 , 0.02 , and $0.01 \mathrm{~mol} / \mathrm{L}$, the Tafel slopes were $0.140,0.170$, and $0.229 \mathrm{~V} /$ decade, respectively.

The reaction kinetics of the oxidation of methanol and ethanol on the Ni/Al-LDH/NMCC electrode was investigated by chronoamperometry. Double step chronoamperograms were recorded by setting the working electrode potentials to the desired values, and these were used to measure the catalytic rate constant on the Ni/Al-LDH/NMCC electrode surface. Figure 9(a) shows the double step chronoamperograms for the Ni/Al-LDH/NMCC electrode in the absence and presence of different concentrations of methanol at the oxidation potential of $710 \mathrm{mV}$ against the $\mathrm{Ag} / \mathrm{AgCl}$ couple. Figure 9(b) shows the plot of the current at a fixed time interval of $15 \mathrm{~s}$ versus the concentration of methanol in the range of 0.01 to $0.08 \mathrm{~mol} / \mathrm{L}$. Good linear plots were observed. The plotting of net current versus minus square root of time gave linear plots (Fig. 9(c)). Therefore, a diffusion controlled process dominated the electrocatalytic oxidation of methanol.

The ratio of the transient current in the presence of
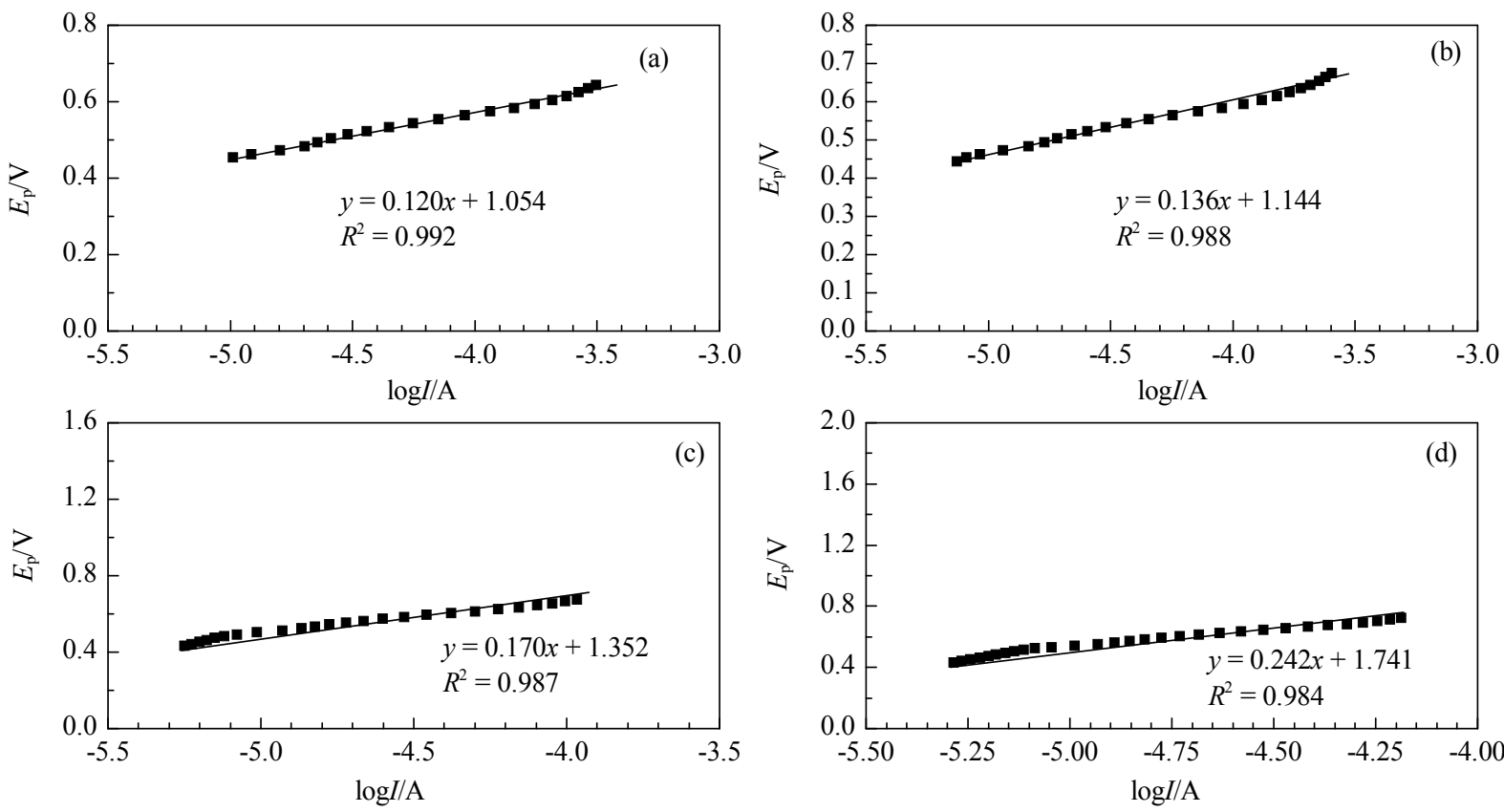

Fig. 8. Tafel slopes obtained for methanol oxidation at the Ni/Al LDH/NMCC electrode at different $\mathrm{NaOH}$ concentrations. The concentration of methanol was $0.05 \mathrm{~mol} / \mathrm{L}$. Potential sweep rate was $5 \mathrm{mV} / \mathrm{s}$. (a) $0.1 \mathrm{~mol} / \mathrm{L} \mathrm{NaOH}$; (b) $0.05 \mathrm{~mol} / \mathrm{L} \mathrm{NaOH}$; (c) $0.02 \mathrm{~mol} / \mathrm{L} \mathrm{NaOH}$; (d) $0.01 \mathrm{~mol} / \mathrm{L} \mathrm{NaOH}$. 

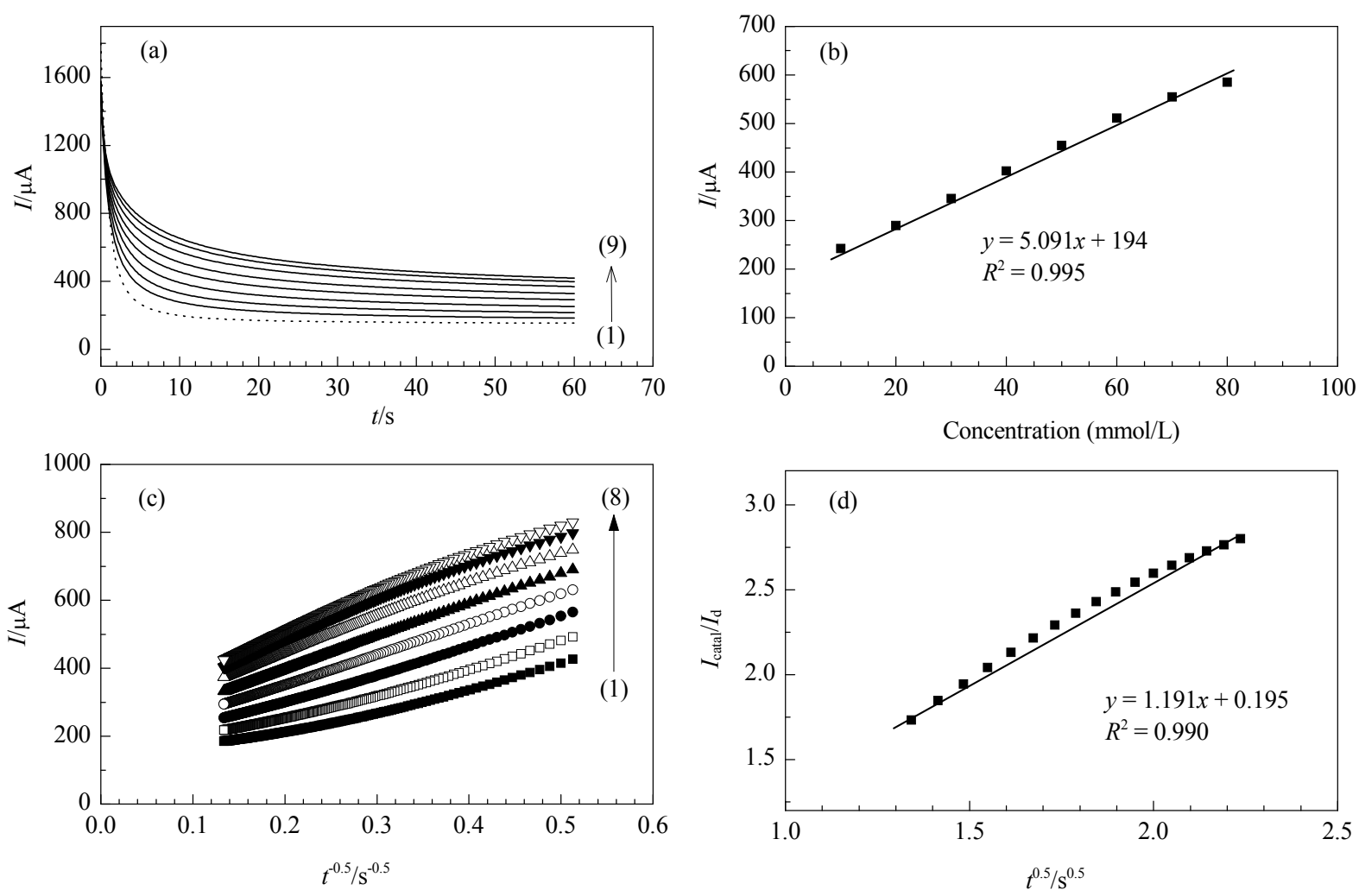

Fig. 9. Chronoamperograms of the $\mathrm{Ni} / \mathrm{Al} \mathrm{LDH} / \mathrm{NMCC}$ electrode in $0.1 \mathrm{~mol} / \mathrm{L} \mathrm{NaOH}$ solution in the absence (1) and presence (2-9) of concentrations of methanol of 0.01 (2), 0.02 (3), 0.03 (4), 0.04 (5), 0.05 (6), 0.06 (7), 0.07 (8), and 0.08 (9) mol/L, respectively (a); chronoamperometric currents at $t=15 \mathrm{~s}$ versus concentration of methanol (b); dependence of transient current on $t^{-1 / 2}$ (c); dependence of $I_{\text {cat }} / I_{\mathrm{d}}$ on $\mathrm{t}^{1 / 2}$ derived from the CAs of (1) and (10) in panel.

methanol to the limiting current in its absence is [34]

$$
I_{\text {cat }} / I_{\mathrm{d}}=\lambda^{1 / 2}\left(\left(\pi^{1 / 2} \operatorname{erf}\left(\lambda^{1 / 2}\right)+\exp (-\lambda) / \lambda^{1 / 2}\right)\right)
$$

where $I_{\text {cat }}$ is the catalytic current in the presence of methanol, $I_{\mathrm{d}}$ the limiting current in the absence of methanol and $\lambda$ $=k \mathrm{c} t(k, c$, and $t$ are the catalytic rate constant, bulk concentration of methanol and the elapsed time, respectively) is the argument of the error function. For $\lambda>1.5, \operatorname{erf}\left(\lambda^{1 / 2}\right)$ almost equals unity and Eq. (3) reduces to [35]

$$
I_{\text {cat }} / I_{\mathrm{d}}=\lambda^{1 / 2} \pi^{1 / 2}=\pi^{1 / 2}(k c t)^{1 / 2}
$$

From the slope of the $I_{\text {cat }} / I_{\mathrm{d}}$ vs $t^{1 / 2}$ plot, the value of $k$ for $0.07 \mathrm{~mol} / \mathrm{L}$ methanol was calculated to be $0.6453 \times 10^{4}$ $\mathrm{cm}^{3} /(\mathrm{mol} \cdot \mathrm{s}$ ) (Fig. 9(d)). Similar chronoamperograms were collected for ethanol. The value of $k$ for $0.06 \mathrm{~mol} / \mathrm{L}$ ethanol was $0.1198 \times 10^{4} \mathrm{~cm}^{3} /(\mathrm{mol} \cdot \mathrm{s})$.

The pseudo-steady state polarization curves of the electro-oxidation of methanol on the $\mathrm{Ni} / \mathrm{Al} \mathrm{LDH} / \mathrm{NMCC}$ electrode at a number of methanol concentrations are presented in Figure 10(a). The rotation rate of the electrode was maintained at $3000 \mathrm{r} / \mathrm{min}$ to avoid the interference of mass transfer in the kinetics measurements. The oxidation began at $483.4 \mathrm{mV}$ (vs $\mathrm{Ag} / \mathrm{AgCl}$ ) and reached a plateau at 684.8 $\mathrm{mV}$ (vs $\mathrm{Ag} / \mathrm{AgCl}$ ) while oxygen evolution started at still higher potentials. In the course of the reaction, the coverage of NiIII increased and reached a saturation (steady state) level, and the oxidation current followed accordingly. According to Eq. (V)

$$
i_{f}=2 F A k_{1} \Gamma k_{2} c_{m} /\left(k_{1}+k_{2}+2 k_{2} c_{m}\right)
$$

The plots of the inverse current against inverse methanol concentration should be linear [36]:

$$
i_{f}^{-1}=\left(F A k_{1} \Gamma\right)^{-1}+\left(\left(\left(k_{1}+k_{-1}\right) / 2 F A k_{1} k_{2} \Gamma\right) c_{m}^{-1}\right.
$$

Figure 10(b) presents the plots of $i^{-1}$ versus $c_{m}{ }^{-1}$ where straight lines at various potentials were obtained. Both the intercepts and slopes of the straight lines in this figure were potential dependent.

The slopes were plotted against $\exp (-n F E / R T)$ with $n=1$ and presented in Fig. 10(c). Using this graph along with Eq. (VI) gave the rate constant of reaction, $k_{2} \Gamma$. The ratio of $k_{-1}^{0} / k_{1}^{0}$ were $3.66 \times 10^{-9} \mathrm{~cm} / \mathrm{s}$ and $8.87 \times 10^{8}$ respectively. Figure $10(\mathrm{~d})$ presents the variation of the intercepts of the lines in Fig. 10(b) with the applied potential on a semi-log plot. Using this graph and Eq.(VI), $k_{1}^{0} \Gamma$ and the anodic transfer coefficient were calculated to be $4.16 \times 10^{-14}$ $\mathrm{mol} /(\mathrm{s} \cdot \mathrm{cm})$ and 0.61 . For ethanol, similar results were obtained. The values of $k_{2} \Gamma, k_{-1}^{0} / k_{1}^{0}, k_{1}^{0} \Gamma$, and $\alpha$ obtained were $1.23 \times 10^{-9} \mathrm{~cm} / \mathrm{s}, 2.38 \times 10^{8}, 1.64 \times 10^{-10} \mathrm{~cm} / \mathrm{s}, 8.09 \times 10^{6}$, and 0.4 , respectively. 

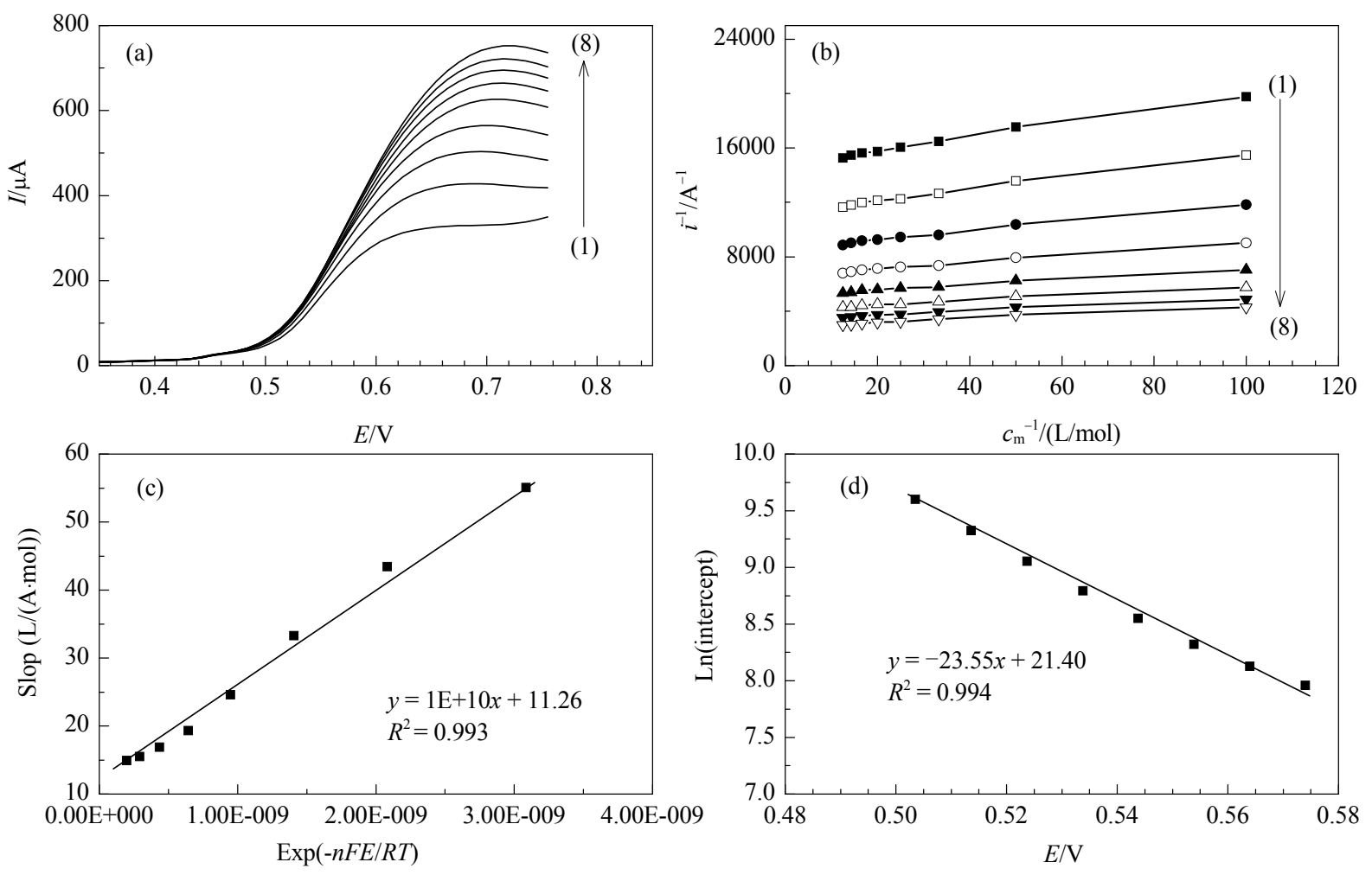

Fig. 10. Pseudo-steady state polarization curves of the Ni/Al LDH/NMCC electrode obtained in 0.01 (1), 0.02 (2), 0.03 (3). 0.04 (4), 0.05 (5), 0.06 (6), 0.07 (7), and 0.08 (8) mol/L methanol (a), plots of $i^{-1}$ against $c_{m}^{-1}$ at various potentials of 503.5 (1), 513.6 (2), 523.7 (3), 533.8 (4), 543.8 (5), 553.9 (6), 564 (7), and 574 (8) $\mathrm{mV} / \mathrm{Ag} / \mathrm{AgCl}$ (b), plot of the slopes (of curves in (b)) vs exp(-nFE/RT) (c), and plot of the Ln(intercepts) (of curves in (b)) vs applied potential (d).

\section{Conclusions}

A Ni/Al-LDH/NMCC electrode was prepared and used for the electrocatalytic oxidation of methanol and ethanol. The modified electrode gave good activity for the electrooxidation of methanol and ethanol. The mechanism of the oxidation changed with the $\mathrm{NaOH}$ concentration in the range of $0.01-0.1 \mathrm{~mol} / \mathrm{L}$. Good stability, good reproducibility, rapid response, and easy surface regeneration and fabrication are the important properties of the new electrode.

\section{References}

1 Pan W H, Jessie Lue S, Chang C M, Liu Y L. J Membr Sci, 2011, 376: 225

2 Ravikumar M K, Shukla A K. J Electrochem Soc, 1996, 143: 2601

3 Du C Y, Zhao T S, Yang W W. Electrochim Acta, 2007, 52: 5266

4 Heinzel A, Barragan V M. J Power Source, 1999, 84: 70

5 Song S, Zhou W, Liang Z, Cai R, Sun G, Xin Q, Stergiopoulos V, Tsiakaras P. Appl Catal B, 2005, 55: 65

6 Shankaran D R, Narayanan S S. Bull Korean Chem Soc, 2001, 22: 816
7 Zen J M, Kumar A S, Tsai D M. Electroanalysis, 2003, 15: 1073

8 Redepenning J G. TrAC-Trend Anal Chem, 1987, 6: 18

9 Mortimer R. J Chem Soc Rev, 1997, 26: 147

10 Farhadi K, Kheiri F, Golzanb M. J Braz Chem Soc, 2008, 19: 1405

11 Sun D, Zhu L, Zhu G. Anal Chim Acta, 2006, 564: 243

12 Wang J. Electroanalytical Chemistry. 2nd Ed. New York: Wiley, 2000. 115

13 McCreery R L. Electroanal Chem, 1991, 17: 221

14 Wang B, Li B, Wang Z, Xu G, Wang Q, Dong S. Anal Chem, 1999, 71: 1935

15 Salimi A, Pourbeyram S. Talanta, 2003, 60: 205

16 Walcarius A. Electroanalysis, 2001, 13: 701

17 Wang J. Anal Chim Acta, 1999, 399: 21

18 Tsionsky M, Gun J, Glezer V, Lev O. Anal Chem, 1994, 66: 1747

19 Miyata S. Clays Clay Miner, 1980, 28: 50

20 Reichle W T. J Catal, 1985, 94: 547

21 Xu Zh P, Lu G Q. Pure Appl Chem, 2006, 78: 771

22 Qiu J B, Villemure G. J Electroanal Chem, 1995, 395: 159

23 Qiu J B, Villemure G. J Electroanal Chem, 1997, 428: 165

24 Ehlsissen K T, Delahaye-Vidal A, Genin P, Figlarz M, Willmann P. J Mater Chem, 1993, 3: 883

25 Roto R, Villemure G. J Electroanal Chem, 2002, 527: 123 
26 Roto R, Yamagishi A, Villemure G. J Electroanal Chem, 2004, 572: 101

27 Scavetta E, Berrettoni M, Giorgetti M, Tonelli D. Electrochim Acta, 2002, 47: 2451

28 Wang Y, Zhang D, Tang M, Xu S, Li M. Electrochim Acta, 2010, 55: 4045

29 Prevot V, Caperaa N, Taviot-Gueho C, Forano C. Crystal Growth Design, 2009, 9: 3646

30 Karim-Nezhad G, Hasanzadeh M, Saghatforoush LA, Shadjou N, Earshad S, Khalilzadeh B. J Braz Chem Soc, 2009, 20: 141

31 Ballarin B, Berrettoni M, Carpani I, Scavetta E, Tonelli D.
Anal Chim Acta, 2005, 538: 219

32 Karim-Nezhad G, Seyed Dorraji P. Electrochimica Acta, 2010, 55: 3414

33 Karim-Nezhad G, Jafarloo R, Seyed Dorraji P. Electrochimica Acta, 2009, 54: 5721

34 Hasanzadeh M, Karim-Nezhad G, Shadjou N, Khalilzadeh B, Saghatforoush LA, Earshad S, Kazeman I. Chin J Chem, 2009, 27: 638

35 Zheng L, Song J. J Applelectrochem, 2011, 41: 63

36 Hasanzadeh M, Karimnezhad G, Mahjani M G, Jafarian M, Shadjou N, Khalilzadeh B, Saghatforoush L A. Catal Commun, 2008, 10: 295 